\title{
The Role of Eph Receptor Tyrosine Kinases and Ephrin Ligands in Hema- topoietic Cell Development and Function
}

\author{
Michael J. Ting and Andrew W. Boyd* \\ Leukaemia Foundation Research Unit, Queensland Institute of Medical Research, Brisbane, Australia
}

\begin{abstract}
The Eph receptor tyrosine kinases form the largest sub-family of the Receptor tyrosine kinases. Eph receptors interact with membrane bound ligands, termed ephrins. Eph-ephrin interactions have significant roles during mammalian development where they mediate such processes as cell adhesion and migration. Although Eph/ephrin expression is low in adult tissues evidence is accumulating which indicates that Eph and ephrins continue to play significant roles in postembryonic tissues. In this review we describe the current understanding of the function of Eph-ephrin signaling in human and mouse hematopoiesis. Ephs and ephrins have been shown to regulate the differentiation of hematopoietic cells, to direct lymphoid development as well as immune function. Whilst much still remains to be learned about the role of Ephephrin signaling in hematopoieis it is already clear that this system exerts important regulatory effects on differentiation, cell migration and effector function. The possibility that these molecules may be therapeutic targets is also discussed.
\end{abstract}

Keywords: Eph Receptor, ephrin, hematopoiesis, T Lymphocyte.

\section{INTRODUCTION}

\section{(a) THE EPH RECEPTOR TYROSINE KINASES (RTKs)}

Since their initial discovery 20 years ago [1] an abundance of knowledge has been gathered into the structure, signaling, regulation and biological functions of the largest group of the receptor tyrosine kinase (RTK) subfamily, the Eph receptors. The Eph RTK family consists of at least 15 members in vertebrates. Eph receptors show considerable conservation in structure and function within the animal kingdom with the overall structure of Eph receptors apparently established before the parazoan-eumetazoan evolutionary split [2]. The Eph RTK have been extensively studied in man, mouse and to a lesser degree the rat. Eph receptors and their membrane bound ligands, the ephrins appear to have widespread expression amongst vertebrates and invertebrates, alike. Eph and ephrins can be classified into two broad sub-groups, the A and B classes, based on receptorligand binding affinities and structural homology. Currently, there are 9 identified receptors of the EphA class (EphA1EphA9) which bind preferentially to ephrin A ligands and 6 receptors of the EphB class (EphB1-EphB6) that bind with high affinity to ephrin B class ligands.

Eph receptors are type I transmembrane proteins composed of an N-terminal glycosylated ligand-binding domain, a transmembrane region and an intracellular catalytic kinase domain. The extracellular region of Eph receptors contains a number of distinct domains including the $\mathrm{N}$ terminal $\beta$ jelly roll domain which principally determines ephrin binding,

*Address correspondence to this author at the Queensland Institute of Medical Research, 300 Herston Road, Herston, Queensland, 4006, Australia; Tel: +61 733062387 ; E-mail: Andrew.boyd@qimr.edu.au cysteine rich EGF-like domains which are involved in receptor dimerisation and two fibronectin Type III regions [3,4]. These domains may play a role in receptor-receptor dimerization interactions; however this has not been examined in Eph receptor function. The intracellular domains of Eph receptors are composed of a juxtamembrane region that contains a regulatory loop [5] followed by a highly conserved protein kinase domain. Following the kinase domain is a SAM (sterile $\alpha$ motif) domain. These domains have demonstrated roles in both homo- and hetero-oligomerization of Eph receptors [6,7], however their role in Eph function remains obscure as deletion of the SAM domain from EphA4 does not adversely effect EphA4 signaling [8]. At the Cterminus of most receptors is a consensus recognition sequence for PDZ (Post-synaptic density protein, Disc large, Zona occludens tight junction protein) domain proteins. PDZ domains are modular protein interaction domains that bind in a sequence-specific manner to short C-terminal peptides or to internal peptides of proteins. These domains are prominently represented in the proteomes of C. elegans, D. melanogaster and mammals, where they frequently occur in multiple copies or are associated with other protein binding motifs. PDZ domains are involved in the assembly of large molecular complexes that perform signaling functions at specific sub-cellular locations. The organization of signaling molecules around a PDZ-based scaffold imparts stability and maintains the integrity of protein-protein interactions, thereby enhancing the rate of signal transduction. Although PDZ domains are clearly important in multimerisation and receptor signaling, their role in Eph receptor function has been little explored and the significance of the lack of this motif in some Eph receptors has not been explored.

\section{(b) THE EPHRIN LIGANDS}

For several years after their discovery the Eph RTKs were designated "orphan receptors" as their ligands were 
unknown. The first ligand to be identified was purified using affinity purification employing an EphA2 extracellular domain absorbent [9]. Sequence analysis of the isolated ligand revealed it was a molecule previously identified as B61, an early response gene induced by tumor necrosis factor (TNF$\alpha)$ in endothelial cells. This ligand has since been renamed ephrin A1 [10]. Ephrin A1 not only binds tightly to EphA2 (dissociation constant of 20-30 nM) but can also activate the tyrosine kinase activity of this receptor, thus providing proof of a functional ligand. Although ephrin A1 was identified as a soluble molecule, later studies discovered that all the Eph receptor ligands are also membrane-bound [11].

In mammals eight ephrin ligands have been discovered and they can be divided into two groups based on structural grounds and preferential binding to EphA or EphB class receptors. Ephrins of the A-class (ephrin A1-A5), which bind to EphA receptors, are bound to the outer leaflet of the plasma membrane via a glycosylphosphoinositol (GPI) linker. The ephrins of the B class (ephrin B1-B3), which interact with EphB receptors, are all transmembrane proteins with a short highly conserved cytoplasmic tail possessing a PDZ-binding motif. Within the cytoplasmic tail of ephrin B ligands there are five tyrosine residues that are conserved between all type B ligands and act as docking sites for downstream signaling molecules during Eph-ephrin signaling $[12,13]$. An interesting feature of Eph-ephrin signaling is ephrin reverse signaling, in which the ephrin ligands actively initiate biochemical signals upon binding to their cognate Eph receptor, thus ephrin ligands can effectively act as receptors.

\section{EPHRIN B SIGNALING}

The ability of the ephrin ligands to transduce signals was first identified with the presence of phosphorylation of the conserved cytoplasmic tyrosine residues of ephrin B ligands after interaction with Eph receptors [14]. These invariant tyrosine residues are phosphorylated by Src family kinases [15]. Once phosphorylated, ephrin B ligands can bind to cytosolic adapter molecules through $\mathrm{SH} 2$ and $\mathrm{SH} 3$ domains or through their PDZ domains [16]. The SH2-domain signaling molecule, Grb4, was observed to bind to phosphorylated residues of ephrin Bs [17]. This adapter protein binds to ephrin B1 and links it to a signaling network targeting the cell's actin based cytoskeleton [17]. A negative regulator of ephrin $\mathrm{B}$ signaling has also been discovered. The phosphatase PTP$\mathrm{BL}$ can bind to ephrin $\mathrm{B}$ ligands via its $\mathrm{C}$-terminal PDZ domain. PTP-BL dephosphorylates ephrin B cytoplasmic domains and can inactivate Src family kinases thereby effectively terminating reverse signaling [18].

Gene targeting studies have revealed the functional significance of reverse signaling in vivo. EphA4 knockout mice have a number of neural defects including disruption of the corticospinal tract (CST), a major motor pathway that controls voluntary movements [19]. It was found that, having crossed the midline, wild-type CST axons were prevented from re-crossing by a mid-line barrier of ephrin B3. In EphA4 $4^{-\sigma_{-}}$and ephrin $\mathrm{B}^{-{ }_{-}}$CST axons were able to re-cross the midline. This resulted in EphA4 null mice having uncoordinated gait, which resembled the hopping of a kangaroo [19]. In addition to the defects in the CST, the anterior commissure (AC), a large forebrain axon tract, failed to form correctly in EphA4 knockout mice. Experiments in which mutant variants of the EphA4 gene, lacking the kinase domain, were introduced into mice using knock-in mutagenesis revealed that this kinase-dead receptor could not rescue the null defects in CST formation, thus confirming the need for an active EphA4 kinase domain for the development of this major axon tract [19]. However EphA4 kinase domaindeficient mutants could completely restore the AC. Evidently the formation of the AC can progress in an EphA4 kinaseindependent manner. As this mutant receptor is incompetent at signaling it was reasoned that this receptor must have been acting as a ligand to activate signaling events responsible for the restoration of the AC. The ephrin B2 ligand was found to be strongly and specifically expressed in the olfactory bulb of embryonic mice (the olfactory bulb and the temporal lobe are connected via the AC) thus identifying ephrin B2 as a likely receptor candidate [8].

\section{EPHRIN A SIGNALING}

Ephrin A ligands are bound to the cell surface by a GPI linker and do not have direct contact with the interior of the cell. Despite this ephrin A ligands are capable of generating signals that have significant impact on cell function. Similar to other GPI linked proteins, ephrin A ligands are localized within specialized membrane domains termed lipid rafts [20]. Lipid rafts are known to be key sites for the formation of signaling complexes and many signaling molecules, including Src family kinases and activated integrin molecules, are preferentially enriched within these membrane domains $[21,22]$. This places ephrin A ligands in a prime position to signal in conjunction with other molecules localized in lipid rafts. Indeed, activation of ephrin A5 by soluble preclustered EphA3-Fc can recruit the Src family kinase Fyn to lipid raft domains [23]. NIH3T3 cells transfected with ephrin A5 increased their adhesion to fibronectin after activation with EphA3-Fc. This increased adhesion was found to be integrin-dependent and was accompanied by redistribution of vinculin, and activation of MAP kinase. Ephrin A reverse signaling is not as well understood as ephrin B ligands. However, greater understanding of the diversity and function of lipid raft microdomains will no doubt bring forth tools to analyse ephrin A reverse signaling in greater detail and reveal the versatility of ephrin A signaling.

\section{(c) BIOLOGICAL OUTCOMES OF EPH-EPHRIN SIGNALING}

Eph-ephrin signaling mediates a range of cellular effects including; migration, cell adhesion and de-adhesion (cell repulsion). Eph receptors and ephrins generate signals that ultimately converge on the actin cytoskeleton. The regulation of cell movement, positioning and adhesion appear to be the primary roles of Eph receptors, however they may also influence other cellular functions like cell survival, proliferation and differentiation. Eph receptors and ephrins are known to be important in both early and late morphogenetic events during vertebrate embryogenesis [24-26]. Eph receptors play key roles in neural development where they function as navigational molecules guiding axon projections $[27,28]$ and in vascular patterning, where they function in endothelial cell migration, proliferation as well as contributing to arterio-venous demarcation during blood vessel formation [29, 30]. 
Eph receptors bring about their effects through the intermediary action of a number of downstream signaling molecules, such as the Rho family of small GTPases (RhoA, Cdc42 and Rac). EphA receptors can activate Rho proteins through an exchange factor called Ephexin [31]. Ephexin is a member of the $D b l$-family and catalyses the exchange of GDP for GTP to activate Rho GTPases. The expression of ephexin appears to be expressed mainly in the nervous system. EphA receptors constitutively bind to ephexin via their kinase domain. Activation of EphA receptors by ephrin A ligands leads to ephexin-mediated activation of Rho and Rho associated kinases (ROCK) resulting in redistribution of actin filaments and axon growth cone collapse [32]. EphB receptors can also activate Rho GTPases but they do not bind to ephexin, however they do interact with other exchange factors for Rho GTPases, namely intersectin [33] and kalirin [34]. Intersectin functions as an exchange factor for $\mathrm{Cdc} 42$. The activity of intersectin can be enhanced via EphB activation, which leads to actin filament extension and branching [33]. Kalirin co-localizes with activated EphB2 and appears to recruit activated Rac to regions of EphB-ephrin B interaction [34].

Eph receptors can interact with a number of other molecules that influence cell function, particularly adhesion and migration. The wide ranging effects of Eph receptors is derived, in part from their ability to modulate the cellular responses produced by important signaling molecules, such as the integrins. The effects of Eph receptor signaling on integrins is complex, often leading to promotion or suppression of integrin function in different cellular contexts or depending on extent of receptor oligomerisation $[35,36]$. Some of the key downstream effectors of integrins can be directly affected by Eph/ephrin signaling. Focal adhesion kinase (FAK) is an important molecule, which associates with activated integrins, promoting the assembly of other key signaling/scaffold proteins, such as paxillin, p130Cas, vinculin, talin and $\alpha$-actinin. These proteins compose the focal contacts made by integrins linking the cell's cytoskeleton to the ECM. Experiments have shown that activation EphA2 can lead to dephosphorylation of FAK followed by loss of integrin-mediated adhesion [37]. Likewise, Activation of EphA2 on vascular smooth cells by ephrinA1-Fc led to a loss of integrin-mediated cell spreading. This effect was not produced by FAK dephosphorylation but was due to inhibition of Rac1 and p21-activated kinase-1 (PAK1) [38]. While EphA2 mediates loss of adhesion in some cell types (prostate cells), other cell types exhibit increased integrin-mediated adhesion when stimulated by ephrin A ligands. In NIH3T3 fibroblast cells, activation of EphA2 leads to phosphorylation of FAK and enhanced cell spreading [39]. Additional pathways affected by Eph signaling include the PI-3 kinase pathway. PI-3 kinase is a multi-subunit enzyme that phosphorylates the D-3 position on the inositol ring of phosphoinsitolides in response to a variety of extracellular stimuli. The phosphotidylinositol lipid products of PI-3 kinase act as secondary messengers leading to a range of cellular responses including proliferation, cell survival and adhesion. These effects are mediated through secondary messengermediated activation of downstream molecules like, p170S6 kinase, Akt (PKB), and ILK (integrin linked kinase). The SH2 domain of the p85 subunit of PI-3 kinases has been shown to associate with activated EphA2 but the functional significance of this interaction remains unknown [40]. The receptor EphA8 interacts constitutively with another subunit of PI-3 kinase, the p110 $\gamma$ subunit. This interaction regulates integrin function in NIH3T3 and 293 cells [41]. While the current data supports a role for the direct activation of the PI3 kinase pathway by Eph receptors, it may also be activated indirectly through the action of small GTPases. The EphA2 receptor, for instance, induces endothelial cell assembly and migration during angiogenesis in a PI3K dependent process through the activation of Rac1 [42].

\section{(d) EPH/EPHRIN EXPRESSION IN NORMAL AND MALIGNANT HEMATOPOIETIC CELLS}

Hematopoiesis and the development of the vascular system are highly inter-dependent processes. Both primitive hematopoietic stem cells and endothelial progenitors are thought to arise early during vertebrate development from a bipotential progenitor cell termed the hemangioblast [43]. Eph receptors and the ephrins have well-established roles in vasculogenesis/angiogenesis and emerging roles in hematopoiesis. The expression of these proteins has been documented in malignant and normal hematopoietic cells. Expression analysis of a panel of 70 continuous human leukemia-lymphoma cell lines revealed that the vast majority expressed EphB4 [44]. Many of these tumour cell lines also coexpressed the ligand for EphB4, namely ephrin B2. Similarly, The EphA3 receptor was identified and cloned from a cell line, LK63, derived from a case of human pre-B ALL [45]. Further investigations revealed this receptor to be expressed in T cell leukemia cell lines, including Jurkat, JM and HSB-2. We have previously shown that EphA3 expression in leukemic cells is controlled by hypermethylation of this gene [46]. Characterization of the EphA3 promoter using restriction enzymes recognizing $\mathrm{CpG}$ sequences and bisulfite sequencing revealed that the level of methylation correlated closely with EphA3 mRNA expression in both leukaemia cell lines and clinical samples. Tumour cell lines that express EphA3 such as LK63 and the T cell leukaemia cell lines Molt-4, Jurkat and JM cells had partial or complete demethylation of the promoter, whereas cell lines that did not express EphA3 such as the B lymphoid leukaemia cell lines, Raji and Nalm-1 revealed significant methylation. These findings were similar in clinical samples of T-ALL and pre-B ALL [46].

The expression of a number of Ephs and ephrins has been identified in both human and murine hematopoietic stem cells (HSC). Microarray analysis of purified populations of HSCs has shown expression of transcripts for EphA1, ephrin A3, ephrin A4 and ephrin B2 [47, 48]. Furthermore, immunohistochemical analysis of human peripheral blood hematopoietic stem cells revealed that all $\mathrm{CD} 34^{+}$cells and the majority of $\mathrm{CD}_{133^{+}}$cells expressed EphA2 while EphB2 was strongly expressed in $\mathrm{CD} 133^{+}$cells, although fifty percent of CD34 ${ }^{+}$cells lacked expression of this receptor [49]. Collectively, these data reveal a heterogenous expression pattern of Eph/ephrins within the hematopoietic stem cell compartment, as well as indicating a potential role in not only regulating stem cell function but also in leukemogenesis. The functional role of these proteins in the regulation of stem cell adhesion, migration and differentiation has not 


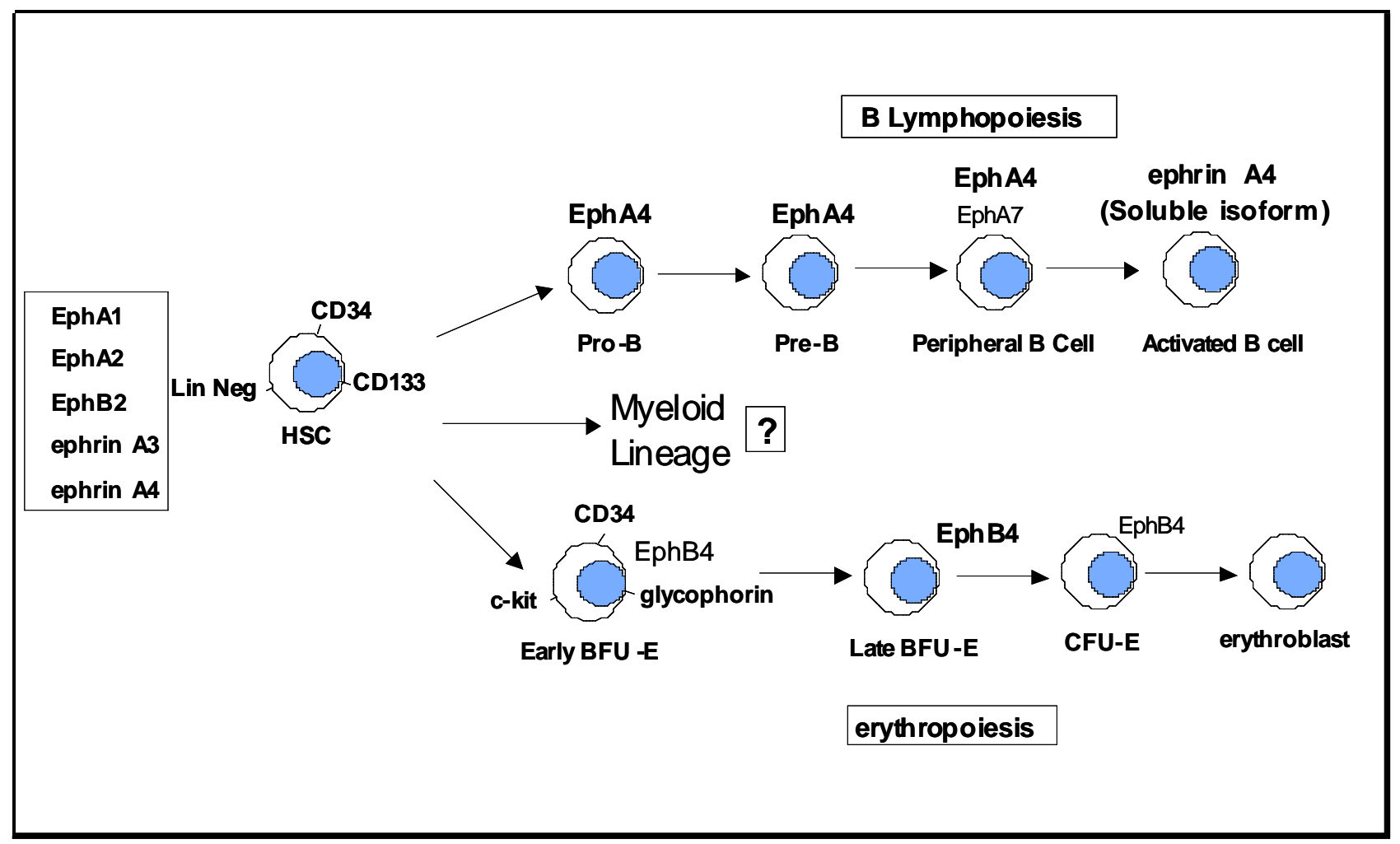

Fig. (1). Expression of Eph and ephrins in human hematopoiesis. Bold type represents strength of expression. Human HSCs express mRNA transcripts for EphA1, EphA2, EphB2, ephrin A3 and ephrinA4. Little is currently known about the expression patterns of Eph/ephrins during myeloid development and most studies conducted on Eph/ephrins in thymocyte development have been conducted in the mouse.

been defined and constitutes a significant area for future investigation.

\section{EPHS AND EPHRINS IN HEMATOPOIETIC PRO- GENITOR CELL DIFFERENTIATION}

Whilst the function of the Eph/ephrin system in stem cells is unknown, there is data to support a role in committed progenitor cells. Examination of normal human bone marrow revealed that EphB4 was expressed in approximately 5\% of bone marrow cells [50]. In addition, these EphB $4^{+}$cells also expressed the stem/progenitor cell marker c-kit and low levels of CD34 and glycophorin. Colony-forming assays with EphB $4^{+} \mathrm{c}-\mathrm{kit}^{+}$cells revealed that they consist exclusively of erythroid progenitors [51]. EphB4 expression on erythroid progenitors is restricted to the early stages of red blood cell development. EphB4 showed expression on immature BFU$\mathrm{E}$ and expression peaked at the late BFU-E stage. EphB4 expression begins to wane around the CFU-E stage of erythropoiesis and becomes essentially undetectable by the early erythroblast cell stage (Fig. 1). In addition to EphB4 expression on erythroid committed progenitors, ephrin B2 expression was also observed in bone marrow stromal cells [51]. Co-culture experiments on stromal cell layers expressing ephrin B2 have confirmed a functional interaction between EphB4 and ephrin B2 in erythropoiesis. FACS sorted EphB $4^{+} \mathrm{c}-\mathrm{kit}^{+}$cells cultured on stroma transfected with either full length or a truncated ephrin B2 showed that ephrin $\mathrm{B} 2^{+}$ stromal cells significantly accelerated maturation of EphB4 ${ }^{+}$ erythroid progenitors. Increased erythroid development was also observed on stroma expressing the truncated form of the ligand (missing cytoplasmic domain) implying that bidirectional signaling is not required for erythropoiesis [51]. EphB4 expression is down-regulated on c-kit ${ }^{+}$cells shortly after contact with ephrin B2 (possibly by proteolytic cleavage and/or endocytosis). Ephrin B2 stimulation of EphB4 ${ }^{+}$ progenitor cells may lead to detachment of progenitor cells from stromal cells and effect differentiation of these cells, possibly by increasing their exposure to soluble cytokines (erythropoietin).

The forced expression of EphB4 in stem cells has a number of significant effects on proliferation and differentiation of hematopoietic progenitor cells. Lentiviral transduction of hematopoietic progenitor cell lines led to a decreased dependence on growth factor (IL-3) and increased the growth rate of these cells in culture [52]. In vitro cultures of primary umbilical cord blood $\mathrm{CD} 4^{+}$cells ectopically expressing EphB4 led to an increase in the number of cells expressing megakaryocytic/erythroid markers. These data imply that EphB4 may act specifically on restricted lineages and affecting a common precursor for the megakaryocytic and erythroid lineages, but appears to have no effect on the granulocyte-monocyte progenitor. Additionally, ectopic expression of EphB4 in hematopoietic cell lines promoted megakaryocytic but not granulocytic or monocytic differentiation providing further evidence that EphB4 signaling selectively affects progenitors committed to the megakaryocytic/erythroid lineages [52]. 
Eph and ephrin expression also appears to play a role in adhesion between hematopoietic stem/progenitors and the bone marrow stroma. Hematopoietic progenitor cell lines cultured on different stromal layers revealed that stroma expressing EphB4 could induce the expression of ephrin B2 on the surface of hematopoietic progenitor cells [53]. Ephrin B2 enhances the adhesion of hematopoietic cells to stroma, as ectopic expression of ephrin B2 leads to increased adhesion and decreased transmigration of hematopoietic cells beneath stromal cell monolayers in vitro [53].

\section{EPHA4 REGULATES PLATELET AGGREGATION}

Expression of EphA4 has not been analysed on hematopoietic cells however is known to be expressed on platelets. It has been shown that ephrin-induced EphA4 signaling can induce platelet aggregation and adhesion to fibrinogen, a process dependant on integrin $\alpha_{\mathrm{II}} \beta_{3}$ engagement [54]. Once platelets have been activated, Eph/ephrin signaling plays a role in perpetuating platelet aggregation and stabilizes the resulting hemostatic plug [55]. EphA4 co-localizes with $\alpha_{\mathrm{IIb}} \beta_{3}$ on the platelet surface during platelet aggregation and EphA4 signaling can phosphorylate the cytoplasmic domain of the $\beta 3$ subunit leading to the binding of myosin and clot retraction [55]. Activated EphA4 has been shown to associate with the Src family kinase members Fyn and Lyn and to activate Rap1 (a member of the Ras superfamily) an important small protein GTPases with links to integrin function in platelets [56].

\section{THE ROLE OF EPHS AND EPHRINS IN LYMPHOID DEVELOPMENT}

Although knowledge concerning the expression and function of Ephs and ephrins in hematopoietic stem cells remains largely unexplored, it is notable that a large body of evidence details the role of this large family of RTKs in the function of more mature blood cells. The most extensively studied hematopoietic lineage with respect to Eph and ephrin biology is the T lymphocyte. In situ hybridisation of mouse thymic tissue shows a highly compartmentalized pattern of expression of members of the EphA class receptors and ephrin A ligands [57]. EphA1, EphA2 and EphA4 expression was restricted to the thymic medulla. We have previously reported that EphA1 is expressed on "epithelial" cells at the cortico-medullary junction in mice [58]. Similarly, EphA2 expression was observed in a population of medullary stromal cells. However, it was unclear whether these are the same cells as those expressing EphA1. Munoz et al. reported EphA4 expression in the epithelial meshwork of the thymic cortex [59]. EphA7 and ephrin A5 were expressed extensively in both the cortex and subcapsule, respectively. However, the expression of these proteins was virtually absent from the medulla [59]. Additionally, EphA3 expression was detected in the medulla and sub-capsule areas. Large ramified EphA3 positive cells were scattered throughout the rat thymic cortex in a distribution similar to ED2 macrophages $[59,60]$.

Interestingly, there is overlap between EphA receptor and ephrin A ligand expression in the thymus. Ephrins A1, A3, and A5 were intensely and broadly expressed in the rat thymus [59]. No ephrin A1 was detected in the thymus using Northern blotting however, in situ hybridisation revealed expression of this ligand in the connective tissue septae during fetal stages of thymic development. Furthermore, it was also expressed in a diffuse manner in the adult rat thymus. Ephrin A3 expression on the other hand is widespread in the thymus with a slightly higher intensity in the medulla [59]. Cortical and medullary thymocytes express ephrin A3 and some epithelial cells are also ephrin A3 positive. In contrast, ephrin A5 expression is most intense in areas surrounding connective tissue trabeculae. The specific pattern of Eph and ephrin expression in the thymus implies a significant functional role in $\mathrm{T}$ cell development.

Treatment of foetal thymic organ cultures (FTOC) with soluble EphA/ephrin A-Fc fusion proteins (EphA1-Fc, EphA2-Fc and EphA3-Fc), which can block endogenous Eph/ephrin interactions, had a number of effects on thymic development. A reduction in all four thymocyte subpopulations, with a particularly marked reduction in the percentages of double positive cells (DP, $\mathrm{CD} 4^{+} \mathrm{CD} 8^{+}$) was observed in treated FTOC lobes [59]. CD8 singly positive (SP) cells were also significantly reduced compared to CD4 SP cells. The reduction in cell numbers within treated cultures was found to be due to increased apoptosis with little effect on the cell cycling status of the different sub-populations.

Ephrin B1 is also expressed in the thymus [61]. Ephrin B1 and EphB receptors are expressed on CD8+ SP cells as well as on DP cells, whereas CD4 SP cells have moderate levels of expression of both EphB receptors and ligands. FTOCs treated with ephrin B1-Fc showed a significant disruption to the normal cellular ratios, producing increased percentages in CD4 SP, CD8 SP and decreased DP cells [61]. Although there were differences in the percentages of the different thymocyte subsets, the total cellularity of the thymus remained fixed. Interestingly, in ephrin B1-Fc treated cultures, all of the cell sub-populations had enhanced proliferation histories. In vitro studies revealed that solid phase ephrin B1-Fc could prevent the apoptosis of thymocytes in response to stimulation with anti-CD3. This antiapoptotic effect was due to the up-regulation of a number of pro-survival molecules such as Bcl-2, Bcl-XL and Flip [61]. Similarly, blocking with ephrin-B1-Fc could enhance apoptosis in thymocytes in vitro. These studies suggest that Eph/ephrin molecules are functionally active within the microenvironment of the thymus and regulate important aspects of $\mathrm{T}$ cell development including proliferation, differentiation and survival. EphB6 is expressed by DP thymocytes and its expression is down-regulated upon maturation of $\mathrm{T}$ cells, as only a small fraction of mature peripheral $\mathrm{CD} 8^{+}$and $\mathrm{CD} 4^{+} \mathrm{T}$ cells express EphB6. Despite this EphB6 does appear to be capable of modulating TCR responses [62-64]. EphB6 knockout mice have normal $\mathrm{T}$ cell development in the thymus and normal mature $\mathrm{T}$ lymphocytes numbers in the peripheral blood. Evidently, EphB6 expression is dispensable for development of thymocytes however EphB6 null mice did have functional defects in mature $\mathrm{T}$ cells. These defects included reduced secretion of cytokines and delayed expression of activation markers, CD25 and CD69, upon activation with an anti-CD3 antibody [62]. Eph receptor knockout strategies, to detect phenotypic differences, are not always successful as the Eph family contains a great deal of functional redundancy. EphB6 null mice exemplify this redundancy, since thymocytes could still be stained with ephrin B- 
Fc despite a lack of EphB6, revealing the expression of other EphB receptors (possibly EphB3 or EphB4) that may functionally substitute for EphB6 [62]. In addition to their roles in $\mathrm{T}$ cell development in the thymus, Ephs and ephrins also regulate functional aspects of mature T cells. EphB/ephrin B signaling can augment $\mathrm{T}$ cell signaling responses as reverse signaling of both ephrin B1 and ephrin B3 on murine T cells was able to enhance both proliferation and cytokine secretion when co-stimulated with antibodies against the $\mathrm{T}$ cell activators, CD28 and CD3 $[65,66]$. These responses are produced; in part by ephrin B mediated activation of the MAPK pathway and demonstrates the co-operation of ephrin reverse signaling with the T cell receptor (TCR) complex. Eph and ephrin signaling has been shown to modulate the chemotactic responses of $\mathrm{T}$ cells toward the potent chemokine SDF$1 \alpha[67,68]$. Binding of EphA1 and ephrin A1enhanced migration of CD4+ $\mathrm{T}$ cells and induced phosphorylation of PYK2, a FAK-like kinase involved in coupling signaling through integrin and chemokine receptors [68]. In contrast, a previous study revealed inhibition of $\mathrm{T}$ cell motility toward an SDF-1 $\alpha$ gradient by ligation of EphA receptors by ephrin A1-Fc on both primary $\mathrm{CD}^{+} \mathrm{T}$ cells and the $\mathrm{T}$ cell leukaemia cell line, Jurkat [67]. This inhibition was due to activation of RhoA and decreased Cdc42 activity resulting in actin cytoskeleton collapse and retraction of cellular processes.

As well as T lymphocytes, Eph and ephrin expression has been documented in human B lymphocytes. EphA4 (Hek8) has broad expression in both human fetal and adult B lymphoid cells [69]. EphA4 mRNA expression could be detected by RT-PCR from the early pro-B cell stage to mature circulating B cells and B cells from tonsils. In contrast, EphA7 expression appears to be developmentally regulated during human B lymphopoiesis. RT-PCR showed abundant expression of EphA7 (Hek11) in foetal bone marrow pro-B and pre-B cells but no or very weak expression in more mature, $\mathrm{sIgM}^{+}$fetal B lineage cells, tonsil B cells, adult pro- and pre$B$ cells and plasma cells [69]. The prominent expression of EphA7 on fetal B lymphoid cells but its absence on adult bone marrow pre- and pro-B cells indicates that this receptor may have a role in the developmental regulation (expansion or differentiation in foetal liver) of these two different populations of B progenitor cells. Ephs and ephrins may also contribute to the immunobiology of mature B cells in peripheral lymphoid tissues. Stimulation of human B cells with an antiIgM antibody led to the expression of a splice variant for ephrin A4. This alternatively spliced transcript encoded a soluble form of ephrin A4 that was secreted by activated B cells [70]. The exact nature of the secreted ligand remains obscure, however one may speculate that the presence of this soluble isoform may act as an antagonist, blocking EphA signaling, and hence modulating the migratory behaviour of B lymphocytes during the immune response.

\section{e) CONCLUSION}

Hematopoiesis is a complex process dependant on numerous factors, both soluble and cell bound to bring about the orderly production of blood cells. Hematopoietic stem cells are thought to reside in a quiescent state within complex micro-environmental niches that act to regulate selfrenewal (cell cycle progression) and cell fate (differentiation). The factors that determine the maintenance of these niches or trigger the migration of hematopoietic stem/progenitor cells into different growth environments are poorly understood. However it almost certainly requires a complex interplay between the extracellular matrix, adhesion molecules and chemokines. The need to precisely delineate the molecular and cellular composition of stem cell "niches" is now of prime importance, as a need for a deeper understanding of stem cell biology has come to the forefront along with the promising technologies of stem cell therapies and regenerative medicine. The expression of Ephs and ephrins by hematopoietic stem/progenitor cells along with their ability to direct differentiation into selective lineages implicates the Eph-ephrin system as novel regulators of hematopoietic niches.

The traditional role of Ephs and ephrins during mammalian development is to co-ordinate the spatial organization of tissues through control of cell migration and adhesion/ repulsion. Given this role it is conceivable that Eph/ephrins may function in a similar manner in hematopoietic tissues, orchestrating cell movement between cellular niches.

A better understanding of the role of Ephs and ephrins in hematopoiesis and blood cell function may lead to the development of improved methods for the treatment of a variety of haematological disorders. This review outlines the evidence for a regulatory role of the Eph/ephrin system in more mature, differentiated blood cells. This remains patchy with little data on myeloid or monocytic cells and only limited data for B lymphocytes. However, in T cells and platelets a more complete picture has been assembled although much work is still required.

As in other systems, Eph/ephrin signaling acts as a regulator rather than a direct effector in most situations. This raises the intriguing possibility that therapeutics directed at these molecules could be used as attenuators rather than complete blockers (or activators), thus allowing a fine control of function which, for example, might be useful in the regulation of platelet function in patients with cardiovascular disease or of T cell function in immunological diseases.

\section{ACKNOWLEDGEMENTS}

We gratefully acknowledge the support of the Leukaemia Foundation of Queensland. MT was supported by an Australian Postgraduate Award from the Australian Government.

\section{REFERENCES}

[1] Hirai H, Maru Y, Hagiwara K, Nishida J, Takaku F. A novel putative tyrosine kinase receptor encoded by the eph gene. Science 1987; 238: 1717-20.

[2] Drescher U. Eph family functions from an evolutionary perspective. Curr Opin Gene Dev 2002; 12: 397-402.

[3] Himanen J, Henkemeyer M, Nikolov D. Crystal structure of the ligand-binding domain of the receptor tyrosine kinase EphB2. Nature 1998; 396: 486-91.

[4] Himanen J, Nikolov D. Eph receptors and ephrins. Int J Biochem Cell Biol 2003; 35: 130-34.

[5] Holland S, Gale N, Gish G, et al. Juxtamembrane tyrosine residues couple the Eph family receptor EphB2/Nuk to specific $\mathrm{SH} 2$ domain proteins in neuronal cells. EMBO J 1997; 16: 3877-88.

[6] Stapleton D, Balan I, Pawson T, Sicheri F. The crystal structure of an Eph receptor SAM domain reveals a mechanim for modular dimerization. Nat Struct Biol 1999; 6: 44-49.

[7] Thanos C, Goodwill K, Bowie J. Oligomeric structure of the human EphB2 receptor SAM domain. Science 1999; 283: 833-36. 
[8] Kullander K, Mather N, Diella F, Dottori M, Boyd A, Klein R. Kinase-dependent and kinase independent functions of EphA4 receptors in major axon tract formation in vivo. Neuron 2001; 29: 7384.

[9] Bartley T, Hunt R, Welcher A, et al. 1 is a ligand for the ECK receptor protein-tyrosine kinase. Nature 1994; 368: 558-60.

[10] Unified nomenclature for Eph family receptors and their ligands, the ephrins. Eph-Nomenclature-Committee. Cell 1997; 90: 403-04.

[11] Davis S, Gale N, Aldrich T, et al. r EPH-related receptor tyrosine kinases that require membrane attachment or clustering for activity. Science 1994; 266: 816-19.

[12] Cerreti D, Vandan Bos T, Nelson N. Isolation of LERK-5: A ligand of the eph-related receptor tyrosine kinases. Mol Immunol 1995; 32: 1197-205.

[13] Song J, Vranken W, Xu P, et al. Solution structure and backbone dynamics of the functional cytoplasmic subdomain of human ephrin $\mathrm{B} 2$, a cell surface ligand with bi-directional signaling properties. Biochemistry 2002; 41: 10942-9.

[14] Holland S, Gale N, Mbamlu G, Yancopoulos G, Henkemeyer M, Pawson T. Bidirectional signaling through the EPH-receptor Nuk and its transmembrane ligands. Nature 1996; 408: 203-6.

[15] Bruckner K, Pasquale E, Klein R. Tyrosine phosphorylation of transmembrane ligands for Eph receptors. Science 1997; 275: 1640-3.

[16] Torres R, Firestein B, Dong H, et al. G. PDZ proteins bind, cluster, and synaptically colocalize with Eph receptors and their ephrin ligands. Neuron 1998; 21: 1453-63.

[17] Cowan C, Henkemeyer M. The SH2/SH3 adapter Grb4 transduces B-ephrin reverse signaling. Nature 2001; 413: 174-9.

[18] Palmer A, Zimmer M, Erdmann K, et al. EphrinB phosphorylation and reverse signalling: regulaton by Src family kinases and PTPBL. Mol Cell 2002; 9: 725-37.

[19] Dottori M, Hartley L, Galea M, et al. EphA4(Sek1) receptor tyrosine kinase is required for the development of the corticospinal tract. Proc Natl Acad Sci USA 1998; 95: 13248-53.

[20] Davy A, Robbins S. Ephrin-A5 modulates cell adhesion and morphology in an integrin-dependent manner. EMBO J 2000; 19: 5396-405.

[21] Mukherjee A, Arnaud L, Cooper J. Lipid-dependent Recruitment of Neuronal Src to lipid rafts in the brain. J Biol Chem 2003; 278: 40806-14.

[22] Leitinger B, Hogg N. The involvement of lipid rafts in the regulation of integrin function. J Cell Sci 2002; 115: 963-72.

[23] Davy A, Gale N, Murray E, et al. Compartmentalized signalling by GPI-anchored ephrinA5 requires the Fyn tyrosine kinase to regulate cellular adhesion. Genes Dev 1999; 13: 3125-35.

[24] Oates A, Lackmann M, Power M, et al. An early development role for Eph-ephrin interaction during vetebrate gastrulation. Mech Dev 1999; 83: 77-94.

[25] Durbin L, Brennan C, Shiomi K, et al. Eph signaling is required for segmentation and differentiation of the somites. Genes Dev 1998; 12: 3096-109.

[26] Chan J, Malby J, Serluca F, et al. Morphogenesis of prechordal plate and notochord requires intact Eph/Ephrin B signaling. Dev Biol 2001; 234: 470-82.

[27] Drescher U, Kremoser C, Handwerker C, Loschinger J, Noda M, Bonhoeffer F. In vitro guidance of retinal ganglion cells by RAGS, a $25 \mathrm{kDa}$ tectal protein related to ligands for Eph receptor tyrosine kinases. Cell 1995; 82: 359-70.

[28] Dufour A, Egea J, Kullander K, Klein R, Vanderhaeghen P. Genetic analysis of EphA-dependent signaling mechanisms controlling topographic modeling in vivo. Development 2006; 133: 441520 .

[29] Adams R, Wilkinson G, Weiss C, et al. Roles of ephrin B ligands and EphB receptors in cardiovascular development: Demarcation of arterial/venous domains, vascular morphogensis, and sprouting angiogenesis. Genes Dev 1999; 13: 295-306.

[30] Zhang X, Takaura N, Inada T, Gale N, Yancopoulos G, Suda T. Stromal cells expressing ephrin B2 promote the growth and sprouting of ephrin B2+ endothelial cells. Blood 2001; 98: 1028-36.

[31] Shamah S, Lin M, Goldberg J, et al. EphA receptors regulate growth cone dynamics through the novel guanine nucleotide exchange factor ephexin. Cell 2001; 105: 233-44.

[32] Wahl S, Barth H, Ciossek T, Aktories K, Mueller B. Ephrin A5 induces collapse of growth cones by activating Rho and Rho kinase. J Cell Biol 2000; 149: 263-70.
[33] Irie F, Yagamuchi T. EphB receptors regulate dendritic spine development via intersectin, $\mathrm{Cdc} 42$ and N-WASP. Nat Neurosci 2002; 5: 1117-8.

[34] Penzes P, Beseer A, Chernoff J, et al. Rapid induction of dendritic spine morphogenesis by trans-synaptic EphrinB-EphB receptor activation of the Rho GEF kalirin. Neuron 2003; 37: 263-74.

[35] Stein E, Lane A, Cerretti D, et al. Eph receptors discriminate specific ligand oligomers to determine alternative signalling complexes, attachment and assembly responses. Genes Dev 1998; 12: 667-78.

[36] Huynh-Do U, Stein E, Lane A, Liu H, Cerretti D, Daniel T. Surface densities of ephrinB1 determine EphB1-coupled activation of cell attachment through $\alpha v \beta 3$ and $\alpha 5 \beta 1$. EMBO J 1999; 18: 2165-73.

[37] Miao H, Burnett E, Kinch M, Simon E, Wang B. Activation of EphA2 suppresses integrin function and causes focal adhesion kinase dephosphorylation. Nat Cell Biol 2000; 2: 62-9.

[38] Deroanne C, Vouret-Craviari V, Wang B, Pouyssegur J. EphrinA1 inactivates integrin-mediated vascular smooth muscle cell spreading via the Rac/PAK pathway. J Cell Sci 2003; 116: 1367-76.

[39] Carter N, Nakamoto T, Hirai H, Hunter T. Ephrin A1 induced cytoskeletal re-organization requires FAK and p130Cas. Nat Cell Biol 2002; 4: 565-73.

[40] Pandey A, Lazar D, Saltiel A, Dixit V. Activation of Eck receptor protein kinase stimulates phosphtidylinositol 3-kinase activity. J Biol Chem 1994; 269: 30154-7.

[41] Gu C, Park S. The EphA8 receptor regulates integrin activity through p110 $\gamma$ phosphatidylinositol-3 kinase in a tyrosine kinase independent manner. Mol Cell Biol 2001; 21: 4579-97.

[42] Brantley-Sieders DM, Caughron J, Hicks D, Pozzi A, Ruiz JC, Chen J. EphA2 receptor tyrosine kinase regulates endothelial cell migration and vascular assembly through phosphoinositide 3kinase-mediated Rac1 GTPase activation. J Cell Sci 2004; 117: 2037-49.

[43] Baron M. Embryonic origins of mammalian hematopoiesis. Exp Hematol 2003; 31: 1160-9.

[44] Steube KG, Meyer C, Habig S, Uphoff CC, Drexler HG. Expression of receptor tyrosine kinase HTK (hepatoma transmembrane kinase) and HTK ligand by human leukemia-lymphoma cell lines. Leuk Lymphoma 1999; 33: 371-6.

[45] Wicks I, Wilkinson D, Savaris E, Boyd A. Molecular cloning of HEK, the gene encoding a receptor tyrosine kinase expressed in human lymphoid tumour cell lines. Proc Natl Acad Sci USA 1992; 89: 1611-5.

[46] Dottori M, Down M, Huttmann A, Fitzpatrick D, Boyd A. Cloning and characterization of the EphA3 (Hek) gene promoter: DNA methylation regulates expression in hematopoietic tumor cells. Blood 1999; 94: 2477-86.

[47] Steidl U, Bork S, Schaub S, et al. Primary human CD34+ hematopoietic stem and progenitor cells express functionally active receptors of neuromediators. Blood 2004; 104: 81-8.

[48] Ivanova N, Dimos J, Schaniel C, Hackney J, Moore K, Lemischka I. A stem cell molecular signature. Science 2002; 298: 601-4.

[49] Lazarova P, Wu Q, Kvalheim G, et al. Growth factor receptors in hematopoietic stem cells: Eph family expression in CD34+ and CD133+ cell populations from mobilized peripheral blood. Int J Immunopathol Pharmacol 2006; 19: 49-56.

[50] Inada T, Iwama A, Sakano S, Ohno M, Sawada K, Suda T. Selective expression of the receptor tyrosine kinase, HTK on human erythroid progenitor cells. Blood 1997; 89: 2757-65.

[51] Suenobu S, Takabura N, Inada T, et al. A role of EphB4 receptor and its ligand, ephrin B2, in erythropoiesis. Biochem Biophys Res Commun 2002; 293: 1124-31.

[52] Wang Z, Miura N, Bonelli A, et al. Receptor tyrosine kinase, EphB4(HTK) accelerates differentiation of select human haematopoietic cells. Blood 2002; 99: 2740-7.

[53] Okubo T, Yanai N, Obinata M. Stromal cells modulate ephrinB2 expression and transmigration of hematopoietic cells. Exp Hematol 2006; 34: 330-8.

[54] Prevost N, Woulfe D, Jiang H, et al. Eph kinases and ephrins support thrombus growth and stability by regulating integrin outside-in signaling in platelets. Proc Natl Acad Sci USA 2005; 102: 9820-5.

[55] Prevost N, Woulfe D, Tanaka T, Brass L. Interactions between Eph kinases and ephrins provide a mechanism to support platelet aggregation once cell-to-cell contact has occurred. Proc Natl Acad Sci USA 2002; 99: 9219-24. 
[56] Prevost N, Woulfe D, Tognoli M, et al. Signaling by ephrin B1 and Eph kinases in platelets promotes Rap1 activation, platelet adhesion, and aggregation via effector pathways that do not require phosphorylation of ephrin B1. Blood 2004; 103: 1348-55.

[57] Vegara-Silva A, Schaefer K, Berg L. Compartmentalization of Eph receptor and ephrin expression in the thymus. Gene Expr Patterns 2002; 2: 261-5.

[58] Coulthard M, Lickliter J, Subanesan N, et al. Characterization of the Epha1 receptor tyrosine kinase: expression in epithelial tissues. Growth Factors 2001; 18: 303-7.

[59] Munoz JJ, Alonso-C LM, Sacedon R, et al. Expression and function of the Eph A receptors and their ligands ephrins A in the rat thymus. J Immunol 2002; 169: 177-84.

[60] Vicente A, Varas A, Moreno J, Sacedon R, Jimenez E, Zapata G. Ontogeny of rat thymic macrophages: phenotypic characterization and possible relationships between different subsets. Immunology 1995; 85: 99-105.

[61] Yu G, Mao J, Wu Y, Luo H, Wu J. Ephrin B1 is critical in T cell development. J Biol Chem 2006; 281: 10222-9.

[62] Shimoyama M, Matsuoka H, Nagata A, et al. Developmental expression of EphB6 in the thymus: lessons from EphB6 knockout mice. Biochem Biophys Res Commun 2002; 298: 87-94.

[63] Freywald A, Sharfe N, Rashotte C, Grunberger T, Roifman C. The EphB6 Receptor inhibits JNK activation in T lymphocytes and modulates T cell Receptor mediated responses. J Biol Chem 2003; 278: 10150-6.

[64] Luo H, Yu G, Wu Y, Wu J. EphB6 crosslinking results in costimulation of T cells. J Clin Invest 2002; 110: 1141-9.

[65] Yu G, Luo H, Wu Y, Wu J. Mouse ephrin B3 augments T-cell signaling and responses to T-cell receptor ligation. J Biol Chem 2003; 278: 47209-16.

[66] Yu G, Luo H, Wu Y, Wu J. EphrinB1 is essential in T cell-T cell co-operation during $\mathrm{T}$ cell activation. J Biol Chem 2004; 279: 55531-9.

[67] Sharfe N, Feywald A, Toro A, Dadi H, Roifman C. Ephrin stimulation modulates T cell chemotaxis. Eur J Immunol 2002; 32: 3745 55.

[68] Aasheim H, Delabie J, Finne E. Ephrin-A1 binding to CD4+ T lymphocytes stimulates migration and induces tyrosine phosphorylation of PYK2. Blood 2004; 105: 2869-76.

[69] Aasheim H, Terstappen L, Logtenberg T. Regulated expression of the Eph-related receptor tyrosine kinase Hek11 in early human B lymphopoiesis. Blood 1997; 90: 3613-22.

[70] Aasheim H, Munthe E, Funderund S, Smeland E, Beiske K, Lotenberg $\mathrm{T}$. A splice variant of human ephrin A4 encodes a soluble molecule that is secreted by activated human B lymphocytes. Blood 2000; 95 : 221-30.

(C) Ting and Boyd; Licensee Bentham Open.

This is an open access article licensed under the terms of the Creative Commons Attribution Non-Commercial License (http://creativecommons.org/licenses/by-nc/3.0/) which permits unrestricted, non-commercial use, distribution and reproduction in any medium, provided the work is properly cited. 